Tohoku J. Exp. Med., 2010, 221, 53-59

\title{
Spinal Alignment and Mobility in Subjects with Chronic Low Back Pain with Walking Disturbance: A Community-Dwelling Study
}

\author{
Naohisa Miyakoshi, ${ }^{1}$ Yuji Kasukawa, ${ }^{1}$ Yoshinori Ishikawa, ${ }^{1}$ Koji Nozaka ${ }^{1}$ and \\ Yoichi Shimada ${ }^{1}$ \\ ${ }^{1}$ Department of Orthopedic Surgery, Akita University Graduate School of Medicine, Akita, Japan
}

\begin{abstract}
Chronic low back pain (LBP) is influenced by numerous factors and often shows a decline in walking abilities. However, the impact of spinal alignment and mobility on this condition and walking disturbance in the general population is unclear. A total of 672 community-dwelling individuals aged 20-94 years (mean, 69 years) in Kamikoani, Akita, Japan were divided into four groups: controls, subjects with no history of LBP $(n=121)$; HLBP group, subjects with a history of LBP $(n=323)$; CLBP group, subjects with chronic LBP without walking disturbance $(n=89)$; and CLBP-WD group, subjects with chronic LBP with walking disturbance $(n=139)$. Differences among groups were investigated in terms of angle of kyphosis, mobility, and inclination of the spine in upright, flexed, and extended positions, all measured using a computerassisted device. HLBP, CLBP, and CLBP-WD groups showed significantly limited lumbar extension compared to controls $(P<0.05)$. The CLBP-WD group showed significantly increased thoracic and lumbar kyphosis angles and spinal inclination compared to the other groups $(P<0.05)$. Among subjects with chronic LBP (CLBP and CLBP-WD groups), associations between walking disturbance and measured variables were examined using logistic regression. According to multivariate analysis, lumbar kyphosis angle in upright position and spinal inclination in extended position were identified as indices associated with the presence of walking disturbance in subjects with chronic LBP. These results indicate that increased lumbar kyphosis and limitation of total spinal extension are important risk factors for walking disturbance in subjects with chronic LBP.
\end{abstract}

Keywords: chronic low back pain; community-dwelling study; spinal alignment; spinal mobility; walking disturbance Tohoku J. Exp. Med., 2010, 221 (1), 53-59. (C) 2010 Tohoku University Medical Press

Low back pain is a primarily cited condition among problems linked to postural imbalance (Jackson and McManus 1994; Tüzün et al. 1999), and is often associated with a decline in walking abilities. Up to $80 \%$ of the population may be affected by low back pain at sometime in their lives (Fast 1988). Particularly in older individuals, low back pain is related, at least in part, to degenerative changes associated with aging (Deyo and Bass 1989; Clark 1991). Chronic or recurrent low back pain is estimated to occur in 35-79\% of patients (van den Hoogen et al. 1997; Croft et al. 1998).

Differences in lumbar lordosis and thoracic kyphosis are primarily cited among the postural changes related to low back pain (Jackson and McManus 1994; Tüzün et al. 1999). Loss of lumbar lordosis correlates well with the incidence of chronic low back pain in adulthood (Glassman et al. 2005; Djurasovic and Glassman 2007). In addition, in the literature on low back pain, much attention has been given to the predictive ability of spinal movements (Troup et al. 1981; Burton and Tillotson 1991; Main et al. 1992; Burton et al. 1995). This relation with the persistence of low back pain could be a direct consequence of spinal restriction. Patients with a less mobile spine may have more severe symptoms such as walking disturbance. However, to the best of our knowledge, no previous community-based studies have concurrently assessed symptoms of chronic low back pain with or without walking disturbance, and spinal alignment and mobility. The objective of the present study was thus to evaluate relationships between chronic low back pain with or without walking disturbance and spinal alignment and mobility among communitydwelling individuals over a broader age range in a district of Japan.

\section{Materials and Methods}

Recruitment activities were designed to enroll a cohort of healthy, ambulatory, community-dwelling individuals $\geq 20$ years old who participated in a public health examination in Kamikoani, Akita,

Received February 17, 2010; revision accepted for publication March 27, 2010. doi:10.1620/tjem.221.53

Correspondence: Naohisa Miyakoshi, M.D., Ph.D., Department of Orthopedic Surgery, Akita University Graduate School of Medicine,

1-1-1 Hondo, Akita 010-8543, Japan.

e-mail:miyakosh@doc.med.akita-u.ac.jp 
Japan. With a population of approximately 2900 , the town of Kamikoani is in a mainly rural (farming/forestry) district and contains one of the highest percentages of elderly subjects among towns in Japan. In $2008,44.5 \%$ of the population was $\geq 65$ years old. Individuals who were institutionalized, unable to walk without the assistance of another person, or unable to provide self-reported data were excluded. A total of 672 eligible subjects in Kamikoani were enrolled in this study, representing approximately $23 \%$ of the total town. Subjects included 240 men and 432 women with a mean age of 69.4 years (range, 20-94 years).

All participants were asked about their history and present status of clinically relevant low back pain and then divided into four groups as follows: control group, subjects with no history of low back pain ( $n=121)$; HLBP group, subjects with a history of clinically relevant low back pain, but no pain at the time of investigation $(n=323)$; CLBP group, subjects with chronic low back pain but no walking disturbance due to low back pain $(n=89)$; and CLBP-WD group, subjects with chronic low back pain with walking disturbance due to low back pain $(n=139)$.

Body mass index $\left(\mathrm{kg} / \mathrm{m}^{2}\right)$, self-reported ambulation time ( $\mathrm{min}$ ), spinal alignment (kyphosis angle) and range of motion (ROM) of the thoracic and lumbar spine, and spinal inclination were measured. The study protocol was approved by the ethics committee of the government health authorities of Kamikoani. All subjects provided written informed consent prior to examination.

\section{Definitions of low back pain and walking disturbance}

Low back pain was considered clinically relevant if the participant answered that pain had occurred more than once and had been moderately to severely bothersome, or if the participant needed any medical treatment. Chronic low back pain was defined if the participant had clinically relevant low back pain lasting for $>1$ year (Kang et al. 2007; Miyakoshi et al. 2007). All other pain episodes were classified as not clinically relevant. If the participant could not walk for $>30$ min due to low back pain, walking disturbance was considered present.

\section{Measurement of spinal kyphosis angles, ROMs, and inclinations}

Kyphosis angles and ROMs of the thoracic (T1-T12) and lumbar (L1-L5) spine were measured using a computerized measurement device of surface curvature (SpinalMouse ${ }^{\circledR}$; Idiag, Volkerswill, Switzerland) in an upright position and at maximum flexion and extension (Miyakoshi et al. 2005). Details regarding this device have been previously published (Post \& Leferink 2004). The device consists of a mobile unit of 2 rolling wheels interfaced to a based station through telemetry. By sliding the mobile unit along the spinal curvature, sagittal spinal alignment is calculated and displayed on the computer monitor. Repeating this process with the patient in flexion and extension of the spine allowed measurement of ROM (Post and Leferink 2004) (Fig. 1). Spinal inclination, which was defined as the angle between the line from the center of $\mathrm{T} 1$ to $\mathrm{S} 1$ and a perpendicular line (Kasukawa et al. 2010), was also measured using SpinalMouse ${ }^{\circledR}$ in an upright position and at maximum flexion/extension. SpinalMouse ${ }^{\circledR}$ delivers consistently reliable values for standing curvatures and ROM (Mannion et al. 2004; Post and Leferink 2004). Post and Leferink (2004) reported that interrater intraclass correlation coefficients (ICCs) for curvature measurement with SpinalMouse ${ }^{\circledR}$ were greater than 0.92. Mannion et al. (2004) reported that the intrarater ICCs ranged from 0.82 to 0.83 , and the interrater ICCs ranged from
A

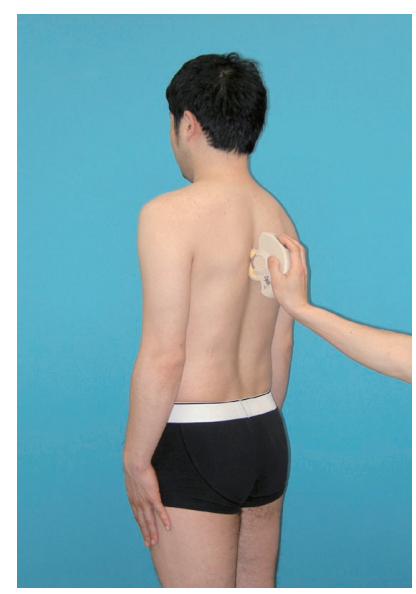

B

$\mathrm{C}$

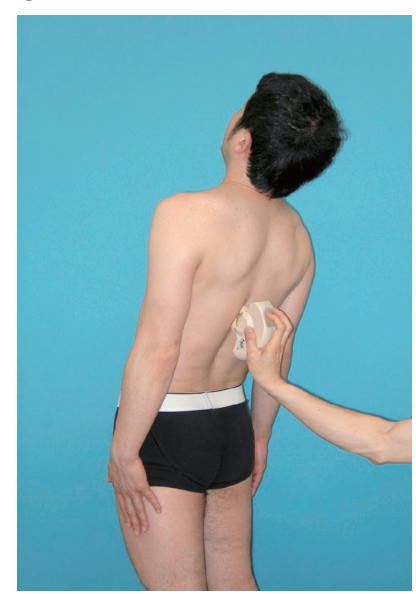

Fig. 1. Measurement with the SpinalMouse ${ }^{\circledR}$ system. A, upright. B, flexion. C, extension.

0.81 to 0.86 . In addition, previous studies showed that the thoracic and lumbar kyphosis angles and spinal ROMs measured with the SpinalMouse ${ }^{\circledR}$ were strongly correlated with those measured with spine radiographs $(r=0.804, r=0.863$, and $r=0.783$, respectively; $P<0.0001$ ) (Miyakoshi et al. 2004).

\section{Statistical analysis}

All data are presented as mean \pm standard deviation (S.D.). Statistical analysis was performed using StatView version 5.0 software (Abacus Concepts, Berkeley, CA). Statistical differences among groups were compared using Fisher's protected least-significant differences method (post-hoc test) for multiple comparisons in a oneway analysis of variance. Correlations between variables were examined using Pearson's correlation coefficient analysis. Logistic regression analysis was used to analyze risk factors for walking disturbance in subjects with chronic low back pain. Values of $P<0.05$ were considered statistically significant.

\section{Results}

Comparisons of measured variables among groups

The CLBP-WD group was significantly older than the other groups (Table 1). Body mass index showed no sig- 
Table 1. Comparisons of measured variables in study subjects.

\begin{tabular}{lccccc}
\hline \multicolumn{1}{c}{ Variables } & Control $(n=121)$ & HLBP $(n=323)$ & CLBP $(n=89)$ & CLBP-WD $(n=139)$ & ANOVA \\
\hline Age (years) & $66.5(14.0)$ & $68.5(10.4)$ & $67.7(12.0)$ & $75.1(6.8)^{\mathrm{a}, \mathrm{b}, \mathrm{c}}$ & $<0.0001$ \\
Body mass index $\left(\mathrm{kg} / \mathrm{m}^{2}\right)$ & $23.6(3.8)$ & $24.0(3.7)$ & $24.4(3.4)$ & $23.9(3.4)$ & 0.4515 \\
Upr Thoracic kyphosis angle $\left(^{\circ}\right)$ & $36.0(9.2)$ & $36.9(9.5)$ & $36.8(10.0)$ & $36.3(12.7)$ & 0.8188 \\
Upr Lumbar kyphosis angle $\left(^{\circ}\right)$ & $-10.9(12.2)$ & $-11.1(11.6)$ & $-10.7(12.3)$ & $1.7(18.1)^{\mathrm{a}, \mathrm{b}, \mathrm{c}}$ & $<0.0001$ \\
Upr Spinal inclination $\left(^{\circ}\right)$ & $5.5(7.0)$ & $4.2(6.0)$ & $4.8(5.8)$ & $10.7(10.5)^{\mathrm{a}, \mathrm{b}, \mathrm{c}}$ & $<0.0001$ \\
Flex Thoracic kyphosis angle $\left(^{\circ}\right)$ & $44.1(10.1)$ & $42.1(11.5)$ & $41.8(12.5)$ & $40.6(13.1)$ & 0.1280 \\
Flex Lumbar kyphosis angle $\left(^{\circ}\right)$ & $17.1(15.8)$ & $17.0(14.8)$ & $17.3(16.1)$ & $25.2(19.9)^{\mathrm{a}, \mathrm{b}, \mathrm{c}}$ & $<0.0001$ \\
Flex Spinal inclination $\left({ }^{\circ}\right)$ & $86.7(27.6)$ & $91.5(25.7)$ & $89.7(25.4)$ & $86.7(27.6)$ & 0.1979 \\
Ext Thoracic kyphosis angle $\left(^{\circ}\right)$ & $23.3(14.4)$ & $23.2(12.2)$ & $25.1(13.3)$ & $27.5(14.2)^{\mathrm{a}, \mathrm{b}}$ & 0.0137 \\
Ext Lumbar kyphosis angle $\left(^{\circ}\right)$ & $-19.5(14.1)$ & $-18.7(12.3)$ & $-18.1(11.3)$ & $-6.9(17.9)^{\mathrm{a}, \mathrm{b}, \mathrm{c}}$ & $<0.0001$ \\
Ext Spinal inclination $\left(^{\circ}\right)$ & $-16.8(12.9)$ & $-17.8(12.5)$ & $-17.8(11.0)$ & $-5.7(15.9)^{\mathrm{a}, \mathrm{b}, \mathrm{c}}$ & $<0.0001$ \\
\hline
\end{tabular}

${ }^{\mathrm{a}, \mathrm{b}, \mathrm{c}}$ Significant differences $(P<0.05)$ between: ${ }^{\mathrm{a}} \mathrm{Control},{ }^{\mathrm{b}} \mathrm{HLBP}$, and ${ }^{\mathrm{c} C L B P}$.

HLBP, subjects with a history of low back pain; CLBP, subjects with chronic low back pain without walking disturbance; CLBP-WD, subjects with chronic LBP with walking disturbance; ANOVA, one-way analysis of variance; upr, upright position; flex, flexed position; ext, extended position; ROM, range of motion.

Data are presented as mean (s.D.)

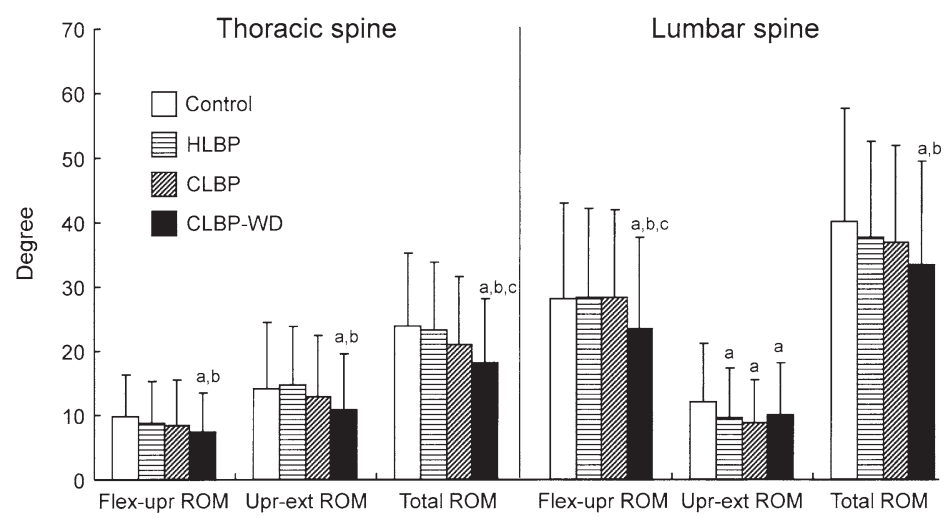

Fig. 2. Spinal range of motion (ROM).

a,b,c Significant differences $(P<0.05)$ between: ${ }^{\mathrm{a}}$ Control, ${ }^{\mathrm{b}} \mathrm{HLBP}$, and ${ }^{\mathrm{c} C L B P}$.

HLBP, subjects with a history of low back pain; CLBP, subjects with chronic low back pain without walking disturbance; CLBP-WD, subjects with chronic LBP with walking disturbance; upr, upright position; flex, flexed position; ext, extended position. Data are presented as mean \pm S.D.

nificant differences among groups. With regard to spinal alignment and mobility, the HLBP, CLBP and CLBP-WD groups showed significantly lower lumbar upright-extension ROM than the control group (Fig. 2). The CLBP-WD group showed significantly higher angles of lumbar kyphosis in upright, flexed and extended positions and spinal inclinations in upright and extended positions, and significantly lower total thoracic ROM and lumbar flexion-upright ROM than the other three groups. The CLBP-WD group also showed significantly higher angle of thoracic kyphosis in the extended position and significantly lower thoracic flexion-upright ROM, thoracic upright-extension ROM and total lumbar ROM than control or HLBP groups. These results indicate that subjects with a history of low back pain or persistent chronic low back pain experience limited lumbar extension, and subjects with chronic low back pain with concomitant walking disturbance show more limited spinal mobility with increased spinal inclination.

\section{Age-related changes in measured variables}

As age is a very important factor for spinal alignment (Milne and Lauder 1974, Tüzün et al. 1999), correlations between age and measured variables were evaluated in each group (Table 2). In the control group, angles of thoracic and lumbar kyphosis and spinal inclinations in upright and extended positions showed significant positive correlations with age, while spinal ROMs in thoracic and lumbar spines showed significant negative correlations with age. The HLBP group showed a similar trend except for age and thoracic upright-extension ROM. In the CLBP and CLBP-WD groups, significant associations between age and spinal alignment or ROMs were only partially observed. These results indicate that age-related changes in spinal alignment and mobility might be interrupted by the existence of chron- 
Table 2. Correlations between age and measured variables in study subjects.

\begin{tabular}{|c|c|c|c|c|}
\hline Variables & Control $(n=121)$ & $\operatorname{HLBP}(n=323)$ & $\operatorname{CLBP}(n=89)$ & CLBP-WD $(n=139)$ \\
\hline Body mass index $\left(\mathrm{kg} / \mathrm{m}^{2}\right)$ & $-0.284 * *$ & -0.030 & $0.257 *$ & -0.141 \\
\hline Upr Thoracic kyphosis angle $\left(^{\circ}\right)$ & $0.277 * *$ & $0.143 *$ & 0.128 & 0.075 \\
\hline Upr Lumbar kyphosis angle $\left(^{\circ}\right)$ & $0.376^{* * *}$ & $0.293 * * *$ & $0.220 *$ & $0.263 * *$ \\
\hline Upr Spinal inclination $\left(^{\circ}\right)$ & $0.348 * * *$ & $0.304 * * *$ & $0.408 * * *$ & $0.270 * *$ \\
\hline Flex Thoracic kyphosis angle $\left(^{\circ}\right)$ & 0.082 & -0.052 & -0.051 & -0.001 \\
\hline Flex Lumbar kyphosis angle $\left(^{\circ}\right)$ & -0.072 & -0.006 & -0.137 & $0.212 *$ \\
\hline Flex Spinal inclination $\left({ }^{\circ}\right)$ & -0.105 & -0.088 & -0.087 & -0.124 \\
\hline Ext Thoracic kyphosis angle $\left(^{\circ}\right)$ & $0.368 * * *$ & $0.139 *$ & 0.093 & 0.081 \\
\hline Ext Lumbar kyphosis angle $\left(^{\circ}\right)$ & $0.261 * *$ & $0.390 * * *$ & 0.164 & $0.321 * * *$ \\
\hline Ext Spinal inclination $\left(^{\circ}\right)$ & $0.380 * * *$ & $0.402 * * *$ & $0.315 * *$ & $0.391 * * *$ \\
\hline Thoracic flex-upr ROM $\left(^{\circ}\right)$ & $-0.203^{*}$ & $-0.231 * * *$ & $-0.218^{*}$ & $-0.220^{*}$ \\
\hline Thoracic upr-ext ROM $\left(^{\circ}\right)$ & $-0.260 * *$ & -0.072 & 0.015 & -0.001 \\
\hline Thoracic ROM $\left(^{\circ}\right)$ & $-0.351 * * *$ & $-0.215 * * *$ & -0.136 & -0.136 \\
\hline Lumbar flex-upr ROM $\left(^{\circ}\right)$ & $-0.380 * * *$ & $-0.242 * * *$ & $-0.353 * * *$ & -0.039 \\
\hline Lumbar upr-ext ROM $\left(^{\circ}\right)$ & $-0.218^{*}$ & $-0.120^{*}$ & -0.124 & -0.125 \\
\hline Lumbar ROM $\left(^{\circ}\right)$ & $-0.435 * * *$ & $-0.292 * * *$ & $-0.379 * * *$ & -0.099 \\
\hline
\end{tabular}

Data are presented as $r$ by Pearson's correlation coefficient.

HLBP, subjects with a history of low back pain; CLBP, subjects with chronic low back pain without walking disturbance; CLBP-WD, subjects with chronic LBP with walking disturbance; upr, upright position; flex, flexed position; ext, extended position; ROM, range of motion.

$$
* P<0.05, * * P<0.01, * * * P<0.001
$$

Table 3. Age-adjusted association between presence of "walking disturbance" and measured variables in patients with chronic low back pain.

\begin{tabular}{|c|c|c|c|}
\hline Variables & Age-adjusted OR & $95 \%$ CI & $P$ \\
\hline Body mass index $\left(\mathrm{kg} / \mathrm{m}^{2}\right)$ & 0.950 & $0.871-1.037$ & 0.2517 \\
\hline Upr Thoracic kyphosis angle $\left({ }^{\circ}\right)$ & 0.989 & $0.964-1.015$ & 0.3999 \\
\hline Upr Lumbar kyphosis angle $\left(^{\circ}\right)$ & 1.046 & $1.021-1.071$ & 0.0002 \\
\hline Upr Spinal inclination $\left(^{\circ}\right)$ & 1.069 & $1.021-1.120$ & 0.0046 \\
\hline Flex Thoracic kyphosis angle $\left(^{\circ}\right)$ & 0.995 & $0.973-1.018$ & 0.6854 \\
\hline Flex Lumbar kyphosis angle $\left(^{\circ}\right)$ & 1.022 & $1.005-1.040$ & 0.0124 \\
\hline Flex Spinal inclination $\left(^{\circ}\right)$ & 0.999 & $0.988-1.010$ & 0.8611 \\
\hline Ext Thoracic kyphosis angle $\left(^{\circ}\right)$ & 1.008 & $0.987-1.031$ & 0.4464 \\
\hline Ext Lumbar kyphosis angle $\left(^{\circ}\right)$ & 1.045 & $1.018-1.072$ & 0.0009 \\
\hline Ext Spinal inclination $\left(^{\circ}\right)$ & 1.055 & $1.025-1.084$ & 0.0002 \\
\hline Thoracic flex-upr ROM $\left(^{\circ}\right)$ & 1.009 & $0.963-1.057$ & 0.7165 \\
\hline Thoracic upr-ext ROM $\left(^{\circ}\right)$ & 0.974 & $0.943-1.006$ & 0.1146 \\
\hline Thoracic ROM $\left(^{\circ}\right)$ & 0.982 & $0.953-1.011$ & 0.2277 \\
\hline Lumbar flex-upr ROM $\left(^{\circ}\right)$ & 0.988 & $0.967-1.009$ & 0.2580 \\
\hline Lumbar upr-ext ROM $\left(^{\circ}\right)$ & 1.032 & $0.992-1.074$ & 0.1221 \\
\hline Lumbar ROM $\left(^{\circ}\right)$ & 0.998 & $0.978-1.018$ & 0.8284 \\
\hline
\end{tabular}

OR, odds ration; 95\%CI, 95\% confidence interval; upr, upright position; flex, flexed position; ext, extended position; ROM, range of motion.

ic low back pain with or without walking disturbance.

Factors associated with walking disturbance in subjects with chronic low back pain

Among subjects with chronic low back pain (CLBP and CLBP-WD groups), age-adjusted associations between walking disturbance and dichotomized outcome variables were examined using logistic regression (Table 3). Increased angles of lumbar kyphosis in upright, flexed, and extended positions and increased spinal inclinations in upright and extended positions represented factors significantly associated with walking disturbance in subjects with 
Table 4. Multivariate logistic regression analysis for "walking disturbance" in patients with chronic low back pain.

\begin{tabular}{lccc}
\hline \multicolumn{1}{c}{ Variables } & OR & $95 \%$ CI & $P$ \\
\hline Upr Lumbar kyphosis angle $\left(^{\circ}\right)$ & 1.044 & $1.001-1.088$ & 0.0442 \\
Upr Spinal inclination $\left(^{\circ}\right)$ & 1.011 & $0.949-1.077$ & 0.7373 \\
Flex Lumbar kyphosis angle $\left(^{\circ}\right)$ & 1.007 & $0.984-1.031$ & 0.5597 \\
Ext Lumbar kyphosis angle $\left(^{\circ}\right)$ & 0.995 & $0.954-1.038$ & 0.8192 \\
Ext Spinal inclination $\left({ }^{\circ}\right)$ & 1.064 & $1.028-1.101$ & 0.0005 \\
\hline
\end{tabular}

OR, odds ration; 95\%CI, 95\% confidence interval; upr, upright position; flex, flexed position; ext, extended position; ROM, range of motion.

Table 5. Correlations between ambulation time (min) and measured variables in patients with walking disturbance by chronic low back pain $(n=139)$.

\begin{tabular}{lrr}
\hline \multicolumn{1}{c}{ Variables } & \multicolumn{1}{c}{$r^{*}$} & \multicolumn{1}{c}{$P$} \\
\hline Age (years) & -0.295 & 0.0003 \\
Body mass index $\left(\mathrm{kg} / \mathrm{m}^{2}\right)$ & -0.009 & 0.9198 \\
Upr Thoracic kyphosis angle $\left(^{\circ}\right)$ & 0.176 & 0.0418 \\
Upr Lumbar kyphosis angle $\left(^{\circ}\right)$ & -0.236 & 0.0059 \\
Upr Spinal inclination $\left(^{\circ}\right)$ & -0.310 & 0.0003 \\
Flex Thoracic kyphosis angle $\left(^{\circ}\right)$ & 0.109 & 0.2088 \\
Flex Lumbar kyphosis angle $\left(^{\circ}\right)$ & -0.203 & 0.0186 \\
Flex Spinal inclination $\left(^{\circ}\right)$ & 0.241 & 0.0050 \\
Ext Thoracic kyphosis angle $\left(^{\circ}\right)$ & 0.006 & 0.9450 \\
Ext Lumbar kyphosis angle $\left(^{\circ}\right)$ & -0.392 & $<0.0001$ \\
Ext Spinal inclination $\left({ }^{\circ}\right)$ & -0.463 & $<0.0001$ \\
Thoracic flex-upr ROM $\left(^{\circ}\right)$ & -0.023 & 0.7942 \\
Thoracic upr-ext $\operatorname{ROM~}\left(^{\circ}\right)$ & 0.266 & 0.0018 \\
Thoracic ROM $\left(^{\circ}\right)$ & 0.223 & 0.0094 \\
Lumbar flex-upr $\operatorname{ROM}\left({ }^{\circ}\right)$ & 0.010 & 0.9063 \\
Lumbar upr-ext $\operatorname{ROM}\left(^{\circ}\right)$ & 0.342 & $<0.0001$ \\
Lumbar ROM $\left(^{\circ}\right)$ & 0.186 & 0.0313 \\
\hline
\end{tabular}

*Correlation between variables as determined by Pearson's correlation coefficient with walking time was scored as: $1,<5 \mathrm{~min} ; 2,5 \mathrm{~min} ; 3,10 \mathrm{~min} ; 4,15 \mathrm{~min} ; 5,20$ $\min ; 6,25 \mathrm{~min}$; and 7, $30 \mathrm{~min}$.

Upr, upright position; flex, flexed position; ext, extended position; ROM, range of motion.

chronic low back pain. Multiple logistic regression analysis including all these significant factors as independent variables revealed angle of lumbar kyphosis in the upright position and spinal inclination in the extended position as indices significantly affecting the presence of walking disturbance in subjects with chronic low back pain (Table 4).

Correlations between ambulation time and measured variables were also evaluated in the CLBP-WD group (Table 5). Ambulation time showed significant positive correlations with angle of thoracic kyphosis in upright position, spinal inclination in flexed position, thoracic upright-extension ROM, total thoracic ROM, lumbar upright-extension ROM, and total lumbar ROM, and significant negative cor- relations with age, angle of lumbar kyphosis in upright, flexed, and extended positions, and spinal inclination in upright and extended positions.

These results indicate that increased lumbar kyphosis in the upright position and increased spinal inclination in the extended position (i.e., limitation of total spinal extension) represent important risk factors for walking disturbance in subjects with chronic low back pain. In addition, once walking disturbance has occurred, ambulation time is also influenced by increased spinal kyphosis and limitation of spinal mobility.

\section{Discussion}

The exact sagittal profile of the spine in subjects with chronic low back pain has still not been exactly defined. Different results are reported for postural changes detected in patients with low back pain. Jackson and McManus (1994) found a significant decrease in lumbar lordosis for the low back pain group compared with normal controls. Results from several other studies support the concept that decreased lumbar lordosis is associated with increased low back pain (Takemitsu et al. 1988; Korovessis et al. 1999; Barrey et al. 2007). Korovessis et al. (1999) reported a greater tendency toward increased thoracic kyphosis in the low back pain group than in controls, with significant differences solely in the sixth decade $(P<0.01)$. Lumbar lordosis was likewise increased in controls compared to the low back pain group, with significant differences solely in the sixth decade $(P<0.001)$ (Korovessis et al. 1999).

However, Hansson et al. (1985) reported no difference in the limits and distribution of angles of lordosis between patients with acute and chronic low back pain and asymptomatic adults. Tüzün et al. (1999) did not detect any significant difference for angles of lumbar lordosis, thoracic kyphosis, and sacral inclination among the low back pain groups and control group. Our results showed no significant differences in any angles of spinal kyphosis between subjects among control, HLBP, and CLBP groups. However, the CLBP-WD group showed significantly increased angles of thoracic and lumbar kyphosis and spinal inclination compared to the other groups $(P<0.05)$.

The present results also indicate that increased lumbar kyphosis in the upright position is a risk factor for walking 
disturbance in subjects with chronic low back pain. In addition, in the present study, significant but weak correlations were observed between ambulation time and both lumbar kyphosis and spinal inclinations in subjects with chronic low back pain. Previous studies have also revealed that abnormal posture is associated with a decline in walking abilities, particularly among the elderly (Hirose et al. 2004). Hirose et al. (2004) evaluated relationships between trunk posture in the sagittal plane and gait ability in a communitydwelling elderly population and showed that lumbar kyphosis, but not thoracic kyphosis, influenced walking performance in elderly subjects aged 65-79 years. Takahashi et al. (2005) evaluated associations between trunk deformities in the sagittal plane and functional impairment to activities of daily living in community-dwelling elderly subjects and demonstrated that the lumbar kyphosis group showed decreased activities of daily living (ADL), manifesting primarily in the basic ADL of walking compared to normal posture, thoracic kyphosis, flat back, and lumbar lordosis groups (Takahashi et al. 2005).

Spinal curvature may be related not only to genetic factors, but also to occupational and environmental factors (Takemitsu et al. 1988). In Asian countries, including Japan and Korea, many elderly people have had a long history of housework or farm work in sedentary or forward-bending postures (Takemitsu et al. 1988; Lee et al. 2001). These working postures often adversely affect the lumbar spine and extensor muscles and cause lumbar kyphosis (Takemitsu et al. 1988; Lee et al. 2001; Kang et al. 2007). This type of lumbar kyphosis (i.e., degenerative flat back or lumbar degenerative kyphosis) is considered to be a rare disease entity in Western countries, but is one of the more common spinal disorders associated with chronic low back pain in Asian countries (Takemitsu et al. 1988; Lee et al. 2001; Kang et al. 2007). The present study was undertaken in rural community-dwelling people, and the majority of participants held or hold agricultural or forestry jobs. Kyphotic changes in these patients may be associated with occupations that require an individual to work in a stooped position under the cultural background in Asia.

We postulate that weakness and fatigability of back extensor muscles is a primary cause of walking disturbance in subjects with increased lumbar kyphosis. Associations between chronic low back pain and reduced muscle strength and increased muscular fatigability have been documented (Mannion et al. 2001). Significant and negative correlations between back extensor strength and lumbar kyphosis have been reported (Miyakoshi et al. 2005; Miyakoshi et al. 2007). Lee et al. (2001) demonstrated that increased lumbar kyphosis caused sagittal imbalance of the spine and its most prominent clinical feature was walking difficulty with a stooped trunk. In contrast, the effectiveness of a sagittal realignment brace for patients with spinal malalignment and walking disturbance has been reported (Weiss and Werkmann 2009). Therefore, weakness and fatigability of back extensor muscles, especially lumbar extensor muscles that influence lumbar kyphosis is thought to be responsible for the walking disturbance in subjects with chronic low back pain.

In addition to spinal alignment, spinal mobility is another important factor for spinal function (Troup et al. 1981; Burton and Tillotson 1991; Main et al. 1992; Burton et al. 1995; Burger et al. 1997; Lee et al. 2001). The present results indicated that subjects with a history of low back pain or persistent chronic low back pain display limited lumbar extension, and that in addition to the increased lumbar kyphosis in upright position, limitation of total spinal extension was another important risk factor for walking disturbance in subjects with chronic low back pain. Once walking disturbance occurred, ambulation time was influenced by the increased spinal kyphosis and limitations to spinal mobility. Consistent with the present results, previous authors have also postulated that abnormal kinematic behavior of the lumbar spine is associated with low back pain (Mayer et al. 2000; Panjabi 2003), and decreased mobility of the spine may lead to increased kyphosis and weakness of the paravertebral muscles, as well as development of impaired physical function (Burger et al. 1997).

The present study has several limitations. First, the study was cross-sectional in design. Longitudinal studies are needed to establish relationships between changes in spinal alignment and mobility and clinical outcomes. Second, our study evaluated spinal alignment at rest. However, sagittal imbalance in subjects with increased lumbar kyphosis may be dynamic rather than static; i.e., spinal balance changes on walking (Lee et al. 2001). Dynamic evaluations such as gait analysis may thus be required to further evaluate individuals with chronic low back pain and walking disturbance. And third, this study did not evaluate the pain intensity. Low back pain itself may cause modifications of spinal curves; therefore limitation of walking ability might be modified with severe pain rather than sagittal imbalance in some subjects. A wide variety of physical and mental outcome scores for low back pain including the Oswestry Disability Index, Roland Morris Disability Questionnaire, and Visual Analogue Scale may help to solve this problem. However, because this study was performed as a part of a public health examination, we had not enough time to obtain these validated questionnaires and scales.

In summary, associations between chronic low back pain with or without walking disturbance and spinal alignment and mobility were investigated in a total of 672 community-dwelling Japanese individuals. Increased lumbar kyphosis and limitation of spinal extension represent important risk factors for walking disturbance in subjects with chronic low back pain.

\section{References}

Barrey, C., Jund, J., Noseda, O. \& Roussouly, P. (2007) Sagittal balance of the pelvis-spine complex and lumbar degenerative diseases. A comparative study about 85 cases. Eur. Spine J., 16, 1459-1467. 
Burger, H., Van Daele, P.L., Grashuis, K., Hofman, A., Grobbee, D.E., Schütte, H.E., Birkenhäger, J.C. \& Pols, H.A. (1997) Vertebral deformities and functional impairment in men and women. J. Bone Miner. Res., 12, 152-157.

Burton, A.K. \& Tillotson, K.M. (1991) Prediction of the clinical course of low-back trouble using multivariable models. Spine, 16, 7-14.

Burton, A.K., Tillotson, K.M., Main, C.J. \& Hollis, S. (1995) Psychosocial predictors of outcome in acute and subchronic low back trouble. Spine, 20, 722-728.

Clark, C.R. (1991) Degenerative conditions of the spine: Differential diagnosis and non-surgical treatment. In The Adult Spine: Principles and Practice. Vol. 2., edited by Frymoyer, J.W., Ducker, T.B., Hadler, N.M., Kostuik, J.P., Weinstein, J.N. \& Whitecloud, T.S. 3rd. Raven Press, New York, NY, pp. 11451164.

Croft, P.R., Macfarlane, G.J., Papageorgiou, A.C., Thomas, E. \& Silman, A.J. (1998) Outcome of low back pain in general practice: a prospective study. BMJ, 316, 1356-1359.

Deyo, R.A. \& Bass, J.E. (1989) Lifestyle and low-back pain. The influence of smoking and obesity. Spine, 14, 501-506.

Djurasovic, M. \& Glassman, S.D. (2007) Correlation of radiographic and clinical findings in spinal deformities. Neurosurg. Clin. N. Am., 18, 223-227.

Fast, A. (1988) Low back disorders: conservative management. Arch. Phys. Med. Rehabil., 69, 880-891.

Glassman, S.D., Bridwell, K., Dimar, J.R., Horton, W., Berven, S. \& Schwab, F. (2005) The impact of positive sagittal balance in adult spinal deformity. Spine, 30, 2024-2029.

Hansson, T., Bigos, S., Beecher, P. \& Wortley, M. (1985) The lumbar lordosis in acute and chronic low-back pain. Spine, 10, 154-155.

Hirose, D., Ishida, K., Nagano, Y., Takahashi, T. \& Yamamoto, H. (2004) Posture of the trunk in the sagittal plane is associated with gait in community-dwelling elderly population. Clin. Biomech. (Bristol, Avon), 19, 57-63.

Jackson, R.P. \& McManus, A.C. (1994) Radiographic analysis of sagittal plane alignment and balance in standing volunteers and patients with low back pain matched for age, sex, and size. A prospective controlled clinical study. Spine, 19, 1611-1618.

Kang, C.H., Shin, M.J., Kim, S.M., Lee, S.H. \& Lee, C.S. (2007) MRI of paraspinal muscles in lumbar degenerative kyphosis patients and control patients with chronic low back pain. Clin. Radiol., 62, 479-486.

Kasukawa, Y., Miyakoshi, N., Hongo, M., Ishikawa, Y., Noguchi, H., Kamo, K., Sasaki, H., Murata, K. \& Shimada, Y. (2010) Relationships between falls, spinal curvature, spinal mobility and back extensor strength in elderly people. J. Bone Miner. Metab., 28, 82-87.

Korovessis, P., Stamatakis, M. \& Baikousis, A. (1999) Segmental roentgenographic analysis of vertebral inclination on sagittal plane in asymptomatic versus chronic low back pain patients. J. Spinal Disord., 12, 131-137.

Lee, C.S., Lee, C.K., Kim, Y.T., Hong, Y.M. \& Yoo, J.H. (2001) Dynamic sagittal imbalance of the spine in degenerative flat back: significance of pelvic tilt in surgical treatment. Spine,
26, 2029-2035.

Main, C.J., Wood, P.L., Hollis, S., Spanswick, C.C. \& Waddell, G. (1992) The Distress and Risk Assessment Method. A simple patient classification to identify distress and evaluate the risk of poor outcome. Spine, 17, 42-52.

Mannion, A.F., Knecht, K., Balaban, G., Dvorak, J. \& Grob, D. (2004) A new skin-surface device for measuring the curvature and global and segmental ranges of motion of the spine: reliability of measurements and comparison with data reviewed from the literature. Eur. Spine J., 13, 122-136.

Mannion, A.F., Taimela, S., Müntener, M. \& Dvorak, J. (2001) Active therapy for chronic low back pain part 1. Effects on back muscle activation, fatigability, and strength. Spine, 26, 897-908.

Mayer, T.G., Robinson, R., Pegues, P., Kohles, S. \& Gatchel, R.J. (2000) Lumbar segmental rigidity: can its identification with facet injections and stretching exercises be useful? Arch. Phys. Med. Rehabil., 81, 1143-1150.

Milne, J.S. \& Lauder, I.J. (1974) Age effects in kyphosis and lordosis in adults. Ann. Hum. Biol., 1, 327-337.

Miyakoshi, N., Hongo, M., Maekawa, S., Ishikawa, Y., Shimada, Y., Okada, K, \& Itoi, E. (2005) Factors related to spinal mobility in patients with postmenopausal osteoporosis. Osteoporos. Int., 16, 1871-1874.

Miyakoshi, N., Hongo, M., Tani, T., Maekawa, S., Shimada, Y. \& Itoi, E. (2004) Relationship between spinal mobility and quality of life in patients with osteoporosis. Osteoporosis Jpn., 12, 143-146. (in Japanese)

Miyakoshi, N., Shimada, Y., Kasukawa, Y., Saito, H., Kodama, H. \& Itoi, E. (2007) Total dorsal ramus block for the treatment of chronic low back pain: a preliminary study. Joint Bone Spine, 74, 270-274.

Panjabi, M.M. (2003) Clinical spinal instability and low back pain. J. Electromyogr. Kinesiol., 13, 371-379.

Post, R.B. \& Leferink, V.J. (2004) Spinal mobility: sagittal range of motion measured with the SpinalMouse, a new non-invasive device. Arch. Orthop. Trauma Surg., 124, 187-192.

Takahashi, T., Ishida, K., Hirose, D., Nagano, Y., Okumiya, K., Nishinaga, M., Matsubayashi, K., Doi, Y., Tani, T. \& Yamamoto, H. (2005) Trunk deformity is associated with a reduction in outdoor activities of daily living and life satisfaction in community-dwelling older people. Osteoporos. Int., 16, 273-279.

Takemitsu, Y., Harada, Y., Iwahara, T., Miyamoto, M. \& Miyatake, Y. (1988) Lumbar degenerative kyphosis. Clinical, radiological and epidemiological studies. Spine, 13, 1317-1326.

Troup, J.D., Martin, J.W. \& Lloyd, D.C. (1981) Back pain in industry. A prospective survey. Spine, 6, 61-69.

Tüzün, C., Yorulmaz, I., Cindaş, A. \& Vatan, S. (1999) Low back pain and posture. Clin. Rheumatol., 18, 308-312.

van den Hoogen, H.J., Koes, B.W., Devillé, W., van Eijk, J.T. \& Bouter, L.M. (1997) The prognosis of low back pain in general practice. Spine, 22, 1515-1521.

Weiss, H.R. \& Werkmann, M. (2009) Treatment of chronic low back pain in patients with spinal deformities using a sagittal re-alignment brace. Scoliosis, 4, 7 . 